\title{
Decolonizing Participatory Design: Memory Making in Namibia
}

\author{
Rachel Charlotte Smith \\ Department of Digital Design and Information Studies, \\ Aarhus University, Aarhus, Denmark \\ rsmith@cc.au.dk \\ Asnath Paula Kambunga \\ Department of Digital Design and Information Studies, \\ Aarhus University, Aarhus, Denmark \\ akambunga@cc.au.dk
}

\begin{abstract}
Participatory Design (PD) approaches seem particularly well suited to contribute to debates over power and decolonization in design, yet often lack considerations of cultural situatedness and underlying ontological entanglements. In this paper we identify theoretical and methodological gaps in PD relating to contemporary discourses of decolonizing design. We integrate perspectives from PD and postcolonial discourse to explore how we can create more far-reaching examples of decolonizing design in practice. We present a study in which young Namibians are at the forefront of knowledge production on postcolonial memories and contribute to discussions of how decolonizing PD practices may be developed through contextualized, transdisciplinary, and transcultural approaches. In particular, we argue there is a need for a "safe space," as well as continuing reflection on methods and de-linking of knowledge and epistemologies within the PD process itself.
\end{abstract}

\section{CCS CONCEPTS}

- Human-centered computing $\rightarrow$ Interaction design; Interaction design process and methods; Participatory design.

\section{KEYWORDS}

Decolonisation, Local epistemologies, Postcolonialism, Knowledge production, $\mathrm{PD}$ methods

\section{ACM Reference Format:}

Rachel Charlotte Smith, Heike Winschiers-Theophilus, Asnath Paula Kambunga, and Sarala Krishnamurthy. 2020. Decolonizing Participatory Design: Memory Making in Namibia. In Proceedings of the 16th Participatory Design Conference 2020 - Participation(s) Otherwise - Vol 1 (PDC '20: Vol. 1), fune 15-20, 2020, Manizales, Colombia. ACM, New York, NY, USA, 11 pages. https://doi.org/10.1145/3385010.3385021

Permission to make digital or hard copies of all or part of this work for personal or classroom use is granted without fee provided that copies are not made or distributed for profit or commercial advantage and that copies bear this notice and the full citation on the first page. Copyrights for components of this work owned by others than the author(s) must be honored. Abstracting with credit is permitted. To copy otherwise, or republish, to post on servers or to redistribute to lists, requires prior specific permission and/or a fee. Request permissions from permissions@acm.org.

PDC '20: Vol. 1, June 15-20, 2020, Manizales, Colombia

(C) 2020 Copyright held by the owner/author(s). Publication rights licensed to ACM. ACM ISBN 978-1-4503-7700-3/20/06 ..\$15.00

https://doi.org/10.1145/3385010.3385021

\author{
Heike Winschiers-Theophilus \\ Department of Computer Science, Namibia University of \\ Science and Technology, Windhoek, Namibia \\ hwinschiers@nust.na \\ Sarala Krishnamurthy \\ Department of Communication, Namibia University of \\ Science and Technology, Windhoek, Namibia \\ skrishnamurthy@nust.na
}

\section{INTRODUCTION}

Contemporary debates of decolonizing design have not yet fundamentally affected the practices that comprise Participatory Design (PD). It could be argued that PD is by its very nature aligned with constructs of decolonization, given that it is politically motivated, challenges existing power structures through bottom-up engagements, and embraces participation by those previously excluded. Muller [33], for example, has posited PD as the "third space" in HCI. "Third space" and "hybridity" are familiar concepts in postcolonial theory associated with Bhabha's [8] assertion that cultural identity is formed in the ambivalent cultures and in-between spaces of the colonizers and the colonized. PD has a long history of addressing power relations and issues of democracy and empowerment; it also has a history of devoting special attention to engaging local and marginalized groups, citizens, and organizations in processes of mutual learning and development [5]. Though the ongoing appropriation of PD outside of Scandinavia, in particular to the Global South, has focused on the inclusion and "empowerment" of local communities and citizens, this has also prompted concerns about the applicability of the original Westernized model to the rest of the world [4].

Contemporary debates on decolonizing design point to the fact that, far from being universal, design practices are still inherently based on Western epistemologies and are applied in developing countries without much consideration for local knowledge systems $[9,14,15,52,54]$. Thus, one could argue that well-intended PD practices still intrinsically promote neocolonial design. Western ways of knowing are deeply embedded in current design thinking and acting, which constrains researchers in future making and methodological reflection. In common with other authors, we argue that the task of decolonizing design discourse is ontological in nature. The radical transformation of design requires a transdisciplinary and transcultural dialogue $[15,40]$.

Schultz et al. [40] suggest that only through the inclusion of marginalized perspectives-such as the previously colonized, indigenous communities and the socio-economically marginalized-can we break out of our own "colonized minds" and manage to achieve plurality in design. This is what Escobar $[14,15]$ terms a pluriversal world, "a world where many worlds fit." We argue that although PD is a loosely coupled approach equipped with a rich toolkit of adaptable tools and techniques for developing new PD practices [11], it does not adequately address the task of decolonizing knowledge in postcolonial contexts. Applied in the context of non-Western 
communities and stakeholders, PD often lacks a deeper attention to and understanding of the cultural realities and ontological entanglements of everyday practices. Moreover, PD's orientation toward future solutions can sometimes lead researchers to fail to recognize the situated historical pasts and presents of local peoples and, in turn, the impact of these upon particular modes of knowledge and meaning making [55]. Despite well-articulated theories of decolonizing design, we still lack practical examples and strategies for a decolonized PD that is capable of dealing with the complex and political realities of postcolonialism.

In an attempt to contribute meaningfully to the decolonizing design discourse, in this paper we report on our recent experiences exploring postcolonialism with young Namibian "Born Frees" and with professional contributors to the Namibian decolonization discourse. This work formed part of a participatory memory-making research project set in postcolonial Namibia. Namibia gained independence in 1990, and colonial legacies are therefore ever-present. Be it in the cityscape, within institutional structures and organizations, or in public media, events and exhibitions-everywhere, everyday narratives incorporate historical and colonial relics intertwined with current socio-economic and political debates. Namibia is undergoing an active decolonization process led by previous independence fighters, contemporary activist groups, and the younger generations of the so-called "Born Free." And like many formerly colonized countries, Namibia is struggling to redefine societal structures and to gain an independent identity. Mbembe [29] remarks that new forms of imperialism and neocolonialism extend decolonization processes enormously. In such instances, local knowledge production and application continue to be subjected to scrutiny both by new local power structures and at the same time by older, colonial reminiscences which continue to suppress local epistemes and indigenous knowledge. It is in the midst of societal movements like these that the deconstruction of (participatory) design can take place and thereby enrich the decolonizing design discourse.

In this paper, we identify theoretical and methodological gaps in $\mathrm{PD}$ in relation to contemporary discourses of decolonizing design. We integrate perspectives from PD and from postcolonial discourse in order to explore how to create more far-reaching examples of decolonizing design in practice. We bring different perspectives to bear on understanding local epistemologies and engaging with communities in environments that are contested and highly political. Our work is framed within a broader transnational research project on participatory memory practices (POEM) in which we explore memory-making in postcolonial Namibia. Based on our empirical work, we reflect on the meanings of "third space," contextualized PD methods, and existing epistemological entanglements.

\section{DECOLONISATION AND DECOLONIALITY}

Decoloniality is located on a theoretical spectrum that extends from colonial discourse at one end to postcolonialism at the other. Postcolonialism is a scholarly conversion that is situated within academic space, as opposed to decolonization, which is much more all-encompassing and transformative [28]. Postcolonial theory also addresses the cultural transformations of nations whose cultures are deeply influenced by those of colonizers. It engages with how these nations are now striving to find their cultural identities in a world where globalization affects contemporary cultures [4]. Gayatri Chakravorty Spivak's seminal essay asks a very important question, "Can the Subaltern Speak?" [47]. The answer here is that the subalterns have always spoken, but it is necessary for intellectuals and researchers to listen to them and engage with them. Opening up this intellectual space is called decoloniality. The discourse of decolonization and decoloniality is a central point of debate, not only in Latin American countries, but also in postcolonial discussions focused on India and several African countries. Researchers in different disciplinary domains have argued that knowledge is itself colonized, and that therefore it first needs to be decolonized. Anibal Quijano [36], for example, points out that the coloniality of power is closely linked to the coloniality of knowledge. Quijano states that modernity and rationality are complicit in that both are exclusionary and totalitarian, whereas in non-imperial languages these concepts do not exist. In line with postmodern theorists critiquing ideas of "grand narratives that suppress micro-histories, Quijano argues that decolonial shifts happen when a "de-linking" of epistemologies takes place [36]. Mignolo [32] states: "de-linking leads to a de-colonial epistemic shift and brings to the foreground other epistemologies, other principles of knowledge and understanding and, consequently, other economies, other politics, other ethics" [p. 453]. Such a de-linking entails a rejection of the (conceptual) separation between "the West" and "the Other," as argued by Said [37]. A focus is thus emphasized on "narratives" and selfrepresentations that reflect the complexities and dynamic variety of human experience in specific contexts, rather than "visions" and grand narratives from afar. Similarly, Winschiers et al. [56] promote a transcultural approach to technology design, one that shifts the focus from deconstructing and comparing cultures to embracing different epistemologies beyond cultural boundaries through a heightened awareness and consciousness of all stakeholders involved. The question for PD is how such theoretical approaches to de-linking and decolonizing can help to shape and articulate PD research methodologies and practices for collaborative knowledge production in and across cultures.

\section{DECOLONISATION IN DESIGN}

Postcolonial theories have been introduced into the design discourse over a period of several decades, with the aim of bridging power and cultural relations between designers and users across continents. The increasing focus on decolonizing design, however, stems as we see it from the continuous lack of de-linking Western epistemologies from current design practices, theories, and forms of knowledge creation. Designing in non-Western contexts, however, provides the opportunity to enrich design with new perspectives, which could lead to enhanced practices and theories encompassing different epistemologies-including the deployment of these within Western contexts so as to create more inclusive mainstream knowledge systems.

\subsection{Postcolonial perspectives on design}

Design and HCI researchers have turned to postcolonial theory to complement design approaches when designing with and for people and contexts formerly colonized [23, 27, 31]. In the setting 
of design projects, postcolonial theory has shown very intensely how projects that "we" undertake for "others" regularly disclose to us knowledge and assumptions about our own cultures [23]. Thus, researchers within PD have recommended the use of postcolonial theory to assist understandings of cultural differences, especially in cross- and intercultural engagements [12, 23, 27, 31].

Within the PD and HCI community, intercultural or cross-cultural differences have always been a challenge. Scholars argue that culture is an important aspect in design, because designers and the participants from different backgrounds may have different cultural values [23]. Winschiers-Theophilus et al. [56] argue that applying different cultural lenses to the design of community-based technologies not only changes processes, but also directs awareness levels, thus developing essentially distinct approaches to cultural interaction. Irani et al. [23] endorse postcolonial theory because of its stance on cultural interactions. They propose the concept of "postcolonial computing" as an approach to remedy problems related to using technologies in new cultural contexts or introducing designs in communities in the global non-West.

In general, PD researchers have been engaged to some extent in discussions around the decolonizing of knowledge. The central political values of PD of democracy, empowerment, and emancipation allow multiple voices and understandings to be in play. The perspectives presented in Muller's concept of the "third space" [33, 34] play a key role in this regard, because the methods and practices of PD are used to create special convergences that can lead to "hybrid spaces" between designers, technology developers, researchers, and the various users and stakeholders in the process. However, the idea that PD offers an in-between domain- "a kind of generalized third space within user centered design” [33]-may in fact counter its applicability to particular cultural and political contexts. As Tlostanova [50] argues, participatory methods such as giving a voice and participation are insufficient to decolonize design. She argues that the doctrine of Western "universalists" in the Global South must be dismissed, because such generalizing principles continue to be used in forms that try to control people's understanding and perspectives.

Conversely, Mainsah and Morrison [27] argue that postcolonial theory has potential to address some of the challenges encountered by PD in addressing "knowledge and power, agency and representation." They argue that postcolonial theory offers cultural understandings and localized means to address the uneven distribution of power that are more powerful than the techniques and methods used in PD. They further argue that these theories help by focusing attention on how such power relations are ingrained and reproduced in design processes and that they could potentially enable the subalterns' epistemes at the margins to resurface [27, 32]. Such approaches open up new ways of creating "cultural hybridity" as designers and participants negotiate power relations [31]. However, recommendations such as those by Mainsah and Morrison [27] and Merritt and Stolterman [31] for using postcolonial theory in PD need to be critically re-examined within a decolonization discourse. Ali [2] criticizes postcolonial theory for failing to address world systems from the "margins, borderlines or periphery." Claiming that postcolonial discourse is more of "Eurocentric critique of Eurocentrism," Ali advocates that decolonial computing should be set to work against the inherently colonial motive in ubiquitous computing and address the specific question "who is thinking / knowing and from where" [2,3]. This is not merely a question of including marginalized voices in the work of designers; designers need to become more fully engaged in people's unfolding lifeworlds. Thus, Winschiers-Theophilus et al. [55] recommend engagements through a transcultural mode rather than focusing on individual or "bounded" cultures. Their argument is that a shift is required from a postcolonial lens to a decolonization approach which emphasizes the need for situated actions.

\subsection{Decoloniality in design}

The emergence of decolonization in design is a response to the subtle and continuing Western colonialism and domination up to the present day, embedded in globalization and capitalism $[9,10,35,40,50]$. According to Smith, [42] decolonization is an attempt to oppose this continuing oppression by generalizing and developing solutions for the "Other." Critical voices argue that decolonizing design aims to distinguish between designs that expedite de-valuing and de-futuring, and designs that promote "de-linking" and redirecting into new ways of being $[16,40]$.

Scholars endeavoring to decolonize design and knowledge argue that the current colonial systems in place need to be opposed so that non-hegemonic ontologies can surface [15, 35]. De O. Martins and De Oliveira [35] argue that for design to be an emancipatory effort, there need to be open spaces where multiple voices are heard through avenues of engaging in constructive arguments. Working from Latin America, their work is situated at the intersection of speculative, critical design and participatory methods. Martins and De Oliveira argue that this space destabilizes the designers' assumptions that participants will design their futures based on personal experiences in the design process [35]. This claim aligns with Escobar's [15] bid for a pluriversal ontological design in which many worlds fit, with a determination to redefine design so as to bring in new and non-exploitative ways of being.

In the setting of Namibia and South Africa, Winschiers-Theophilus and Bidwell [54] point to the fact that Western epistemologies are ingrained in existing paradigms in design, with the consequence that its biases on practices, methods, and values are inseparably present. The authors argue for HCI practices that are informed by local knowledge systems, such as performance-based oral history and a shared understanding of spirituality. Endorsing African-based philosophies and theories such as Ubuntu and Afrocentricity not only promotes more appropriate local technology design, but enriches $\mathrm{HCI}$ as a research field and educational practice through a more diverse array of knowledge systems and paradigms [54].

Adopting traditional or indigenous practices in PD has been considered to be one step in decolonizing methods, because it addresses the "situatedness of the researcher" and therefore inherently tackles power relations within design practices [6]. Storytelling, for example, is not only used in PD in design practices as a way of eliciting information from users [13], but creates a space of mutual understanding where the designer is not merely an observer or facilitator, but is fully engaged and can share their own experiences in the design process $[6,11]$. 


\subsection{Localised design knowledge creation}

In general, Eurocentric approaches to design research discriminate against knowledge and research contributions from the Global South. Bidwell [9] observes that a major problem in $\mathrm{HCI}$ is that African researchers engaging in collaborative research do not get the same roles in research projects as their counterparts from the first world. She also points to the lack of publications by African researchers in the ACM digital library, specifically in the Human Factors in Computing Systems (CHI) conference proceedings. People from the African continent are often seen as illiterate, underdeveloped, and impoverished users of HCI rather than empowered agents and knowledge creators [9]. Further, when the attempt is made to publish local research (of global significance), reviewers have often misread and misjudged contributions because of their lack of insight into local contexts and epistemologies, with the result that the dissemination of such knowledge is prevented. Another example is review processes in which the motivations behind decolonization are easily misconceived due to the political entanglements inherent in these processes. This paper, for example, in which researchers from the Global South and North framed their approach to decolonization by working constructively together, has been criticized for being framed within the terms of the neocolonial and neoliberal project and merely assuming the guise of inclusive and emancipatory development. Such challenges have been discussed at new forums such as HCIxB [21]. The strengthening of local SigCHI chapters has been agreed with the aim of promoting the creation and publication of local research paradigms and results. Recent AfriCHI and ArabHCI initiatives are themselves examples of efforts of decolonizing HCI research, as they represent communities that are usually subjects of research rather than recognized as active collaborators in, or drivers of, HCI research $[1,9,52]$.

Debate over the decolonizing of knowledge and research approaches is therefore a crucial component of PD and must be included in its practices. Nuanced approaches and rich empirical examples that demonstrate how the decolonizing of design might work in situated practice-which consequently contribute to theory building-are absent from the literature of PD. PD research needs to comprise rich contextual descriptions that support understanding of individuals and groups from diverse contexts and the importance of their historical and socio-political pasts and presents [12]. Here contributions to design anthropology and participatory design can also offer decolonizing approaches to the situated ethics and politics of collaborative future-making [20, 43, 44, 46, 52]. Researchers argue for using anthropological approaches to create "correspondence" through a continued engagement with particular people [22] through collaborative explorations of "situated possibilities, formations and actions at the intersection of design and everyday life" [24]. Such culturally situated approaches to knowledge production form the basis of the research we present here. They have the potential to generate new understandings and practices in the decolonization of PD.

\section{PARTICIPATORY MEMORY-MAKING}

Our contribution forms part of a larger European Union Horizon 2020 project on Participatory Memory Practices (POEM, 2018-2021). This project is focused on empowering individuals and groups from differing social and cultural backgrounds to contribute to future development of European societies. The project's focus on participation and inclusiveness in knowledge production prompted its Danish partner to work with a collaborator in Namibia to conceptualize the current sub-project on memory-making with youth in postcolonial Namibia. The aim was to contribute to decentering the Eurocentric focus in many EU-funded projects by devoting attention to the politics and entanglements of contemporary knowledge systems and memory practices, and including diverse and marginalized global contexts in the remit of the project. Moreover, the project's emphasis on Namibia's recent colonial history in a large-scale EU-funded project added political emphasis to the importance of cross-cultural knowledge production and their global politics. ${ }^{1}$ Our ongoing research case explores the everyday realities of young people in Namibia. Participatory design and design anthropological approaches engage local participants in exploring everyday experiences of postcolonialism and in creating possible alternative futures [20]. Rather than tangible design outcomes, the design process addresses the production of new understandings, opportunities and imaginaries for the "Born Free" generation-young people born since independence in 1990. This is achieved through a situated focus on future memory-making, based on the social, cultural, and political values of the local stakeholders [55].

Our research team was comprised of four people: $\mathrm{PhD}$ researcher in POEM based at Aarhus University in Denmark, who is herself a Namibian Born Free; a "third-culture" researcher living in Namibia, mother to two Born Frees and engaged in community-based technology design practices that work to promote and digitize indigenous knowledge; a Danish researcher in design anthropology and participatory design, trained as an anthropologist and partner in the POEM project; and a Namibian-based researcher in the humanities with a special focus on decoloniality and postcolonial narratives. The dual positioning of the $\mathrm{PhD}$ researcher as both insider and outsider [48], as a part of the local youth culture, and as integrated in the Danish and European research context was instrumental in engaging young people in the project and in understanding the socio-political and historical contexts in Namibia. Thus, we position our work in a contemporary transcultural design space of $\mathrm{PD}$, design anthropology, indigenous cultures, and future-making practices.

\subsection{Research design and methodology}

The research reported on here was conducted during a six-month fieldwork in Namibia's capital Windhoek between May and November 2019. It involved a group of ten young Namibians (aged 20-29), four females and six males, working and studying in Windhoek. The young people were recruited through youth-led online communities, project presentations in local organizations, and through personal local networks. The youth were all "born free," as people are termed who were born after independence in 1990. Some are active on social media, for example in Facebook groups addressing issues relating to postcolonialism, such as land allocation and redistribution. They represent different ethnic groups, although most of

\footnotetext{
${ }^{1}$ One more sub-project focusing on youth in postcolonial Greenland was included by the Danish partner researchers in POEM, two design anthropologists at Aarhus University.
} 
them belong to the Aawambo tribe, which represents the majority in the country, to which the researcher herself also belongs. These are resourceful and outspoken young people with an interest in engaging in postcolonial discourses despite the politics of voicing such concerns. Ethnographic interviews were conducted with participants in the first month, and allowed for insights to be gained local youth cultures and for discussions on motivations for participating in the research process, as well as the project goals, roles, and opportunities. In the following two months, the young people engaged in collaborative inquiries into the postcolonial memories ingrained in their present everyday lives. The process was structured around weekly sessions in which the $\mathrm{PhD}$ researcher and the local researcher framed a series of collaborative inquiries. The young people participated in the research design from the first sessions, at which negotiations and plans for the four-month period were agreed.

Two additional groups of stakeholders were also involved in the process. Twelve local contributors to the decolonization discourse were engaged in a workshop to explore present-day perspectives on decolonization in Namibia and to discuss the decolonizing approaches and PD methods used in the research. The discourse contributors represented a range of different fields and institutions: local artists driving the decolonizing arts movement, academics in humanities fields leading a theoretical decolonization discourse, and representatives of AfriCHI chapter, cultural centers, and government institutions. This was a diverse group. Additionally, in order to engage with the young people's work and collaboratively explore and prototype possible solutions for co-creating future memories, a group of five interaction design students from the Namibia University of Science and Technology were engaged to co-design interactive prototypes with the young people, as a part of their course to be run by the researchers. The latter engagement resulted in the codesign of a prototype exhibition on postcolonial narratives of the Born Free at the Independence Memorial Museum (October 2019). This paper does not include the process of the exhibition design All sessions were audio, photo, and video recorded, and they were analyzed for cross-cutting themes that were discussed in regular sessions between the researchers.

\subsection{Colonization and decolonization of Namibia}

Central to studying the young people's local context is understanding Namibia's long colonial history (1884-1990). During this period the country was colonized first by Germany until 1915, and then by neighboring South Africa until 1990, when negotiations and interventions from the United Nations finally ended the colonial era [53]. Under the German colonization, Namibia was known as German South West Africa. Even in a short span of 31 years, Germany managed to leave several permanent prints. These are visible in, for instance, the urban scenery of the capital, Windhoek, with its colonial buildings and monuments [7, 26]. The South African administration was infamous for applying apartheid laws, which kept Namibians segregated based on race and ethnicity [36]. This colonial era was distinguished by the rise of anti-colonial movements and of the current ruling political party, the South West Africa People's Organization, formed to resist South African rule.
A general concern in postcolonial memory-making is the "grand narrative" whereby the formal narrative of a nation-state is determined and articulated by people in power. The contemporary "grand narrative" of Namibia, for instance, has been written by the SWAPO party, whose members were freedom fighters and liberated the country from the previous colonial masters. In this scenario, other micro-stories are submerged and silenced in the main narrative of the country. Young people in Namibia born since independence do not have first-hand colonial experience, but live among postcolonial memories ingrained in contemporary cityscapes, infrastructures, and socio-political processes and narratives [41]. According to Saunders [38], it is not clear when the decolonization process began in Namibia or Southern Africa. His definition of decolonization as "a process leading to the ending of colonial rule" with a fluid handover of power in fact points to the process seen in many African countries, in which one elite group takes over from another, opening up windows of neocolonialism. Many initiatives by government and by activist groups can be seen as efforts to decolonize contemporary Namibia. Social media conversations among young people address issues and accounts of the past in overt acts to reclaim land and social equalities. Local artists highlight issues relating to postcolonialism, such as Hildegard Titus's photo and video exhibition in Windhoek, "Us Now," which addresses critical issues of heritage, identity, and representation of Namibian youth [49].

The question of identity is particularly complex in contemporary Namibia, consisting as it does of more than eleven ethnicities which still widely live separated in terms of culture, locations, and even socio-economic status despite a national push for unification without losing diversity [51]. In an effort to decolonize the physical space, the government has initiated a process to rename streets with German or South African names after local and African heroes and heroines [30]. A Namibian anti-colonial Independence Memorial Museum has been constructed between two well-known colonial sites: the German Protestant church Christuskirche and the Equestrian Reiterdenkmal monument, erected in 1915 to commemorate the German soldiers and civilians who died in the war against local Herero and Nama populations [7].

Such acts can be seen as forms of decolonization. However, we see these initiatives as public service initiatives and grass-roots struggles in the public sphere which however differ from the personal and everyday narratives of younger generations. Their voices are not sought after, as these generations are considered to be the lucky ones, born after independence. Thus, we propose a participatory approach to decolonizing memory-making with Born Frees, co-creating spaces for their voices to become part of the collective memory and shape possible alternative futures.

\section{DECONSTRUCTING DECOLONIZATION IN NAMIBIA}

In the following we present the first phases of the participatory memory-making research, namely the exploration and deconstruction of postcolonization as part of everyday life and emergent cultural practices [45]. 


\subsection{Sessions with the Born Frees}

We facilitated weekly group sessions of two to five hours over the course of two months, exploring the "postcolonial everyday" lives and memories of Born Frees. After initial reservations, the Born Frees engaged in lively dialogues, unwilling to end the sessions and expressing gratitude for the opportunity and space to share their personal thoughts and experiences.

5.1.1 Are Born Frees really free. During the first group session, the young people were invited to do a short role-play in pairs about the everyday experiences as Born Frees in relation to the colonial past. They were encouraged to express their feelings about being "born free," which resulted in several experiences of being told by older generations, "You are too young to know anything about colonial times" or "We died for this country, we have the right to claim what we want." Although the young people did not know each other, they became deeply engaged in personal debates, voicing strong feelings. Some stated they were always victimized by the older generation because they had not been part of the independence struggle; some felt guilty for not being born earlier so they could have been a part of these "comrades." Others expressed a feeling of heavy responsibility to bring positive change to their society because they had had more opportunities than previous generations. One youth pointed out that he did not feel "Born Free," because his San ethnic group continued to be discriminated against and oppressed by other larger ethnic groups.

5.1.2 Common goal setting. To align group and individual goals, and to ensure the commitment of the participants, we deployed a goal-setting workshop adapted from other local researchers $[18,19]$. After identifying central challenges and objectives of the group, the young people reached agreement on a common goal: to be "agents to bridge today for tomorrow," recognizing and appreciating the past actions of current leaders and creating awareness of their experiences among fellow youth and the wider Namibian public (figure 1). The young people committed to engaging in the process for a period of five months, culminating in some form of public exhibition. Among the individual goals contributing to the group goal were "To develop a platform that inspires others to speak out," and "Appreciating the past and working toward creating the future we want." The desire for agency and for change was thus strongly expressed. Possible obstacles preventing the young people from achieving these goals were categorized as internal (within oneself) including fear of not being able to achieve their common goal, and external (outside influence), relating to older generations' unwillingness to change their mindsets, fear of public criticism, and not having the right platform to present the outcomes of the project.

5.1.3 Probing postcolonialism in everyday life. In another session, we probed the youth for legacies of colonialism in their everyday life. Probing the postcolonial realities of the youth, as a method, was inspired by Gaver et al. [17] allowing for sharing perceptions, perspectives and values through cultural probes, and Klaveren's [25] use of probing as a decolonizing approach for storytelling. We asked the youth to collect and bring artifacts (stories, images, audios and videos) from their everyday life reminding them of the colonial past. It turned out that the youth were reluctant to bring

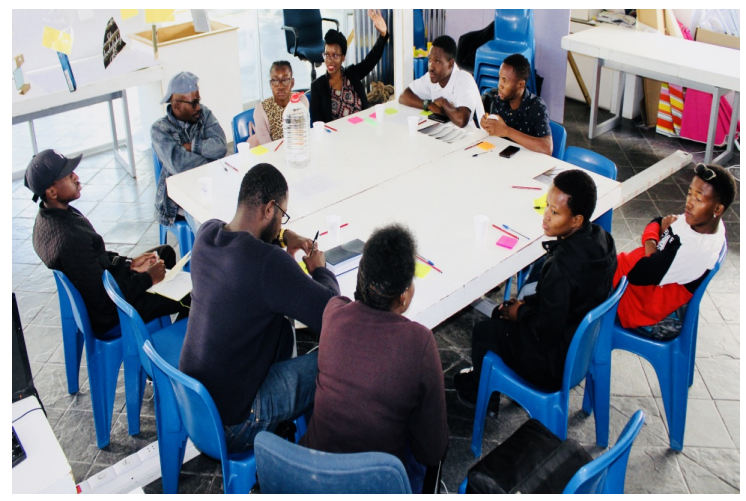

Figure 1: Youth participants debating common goals. @AP Kambunga

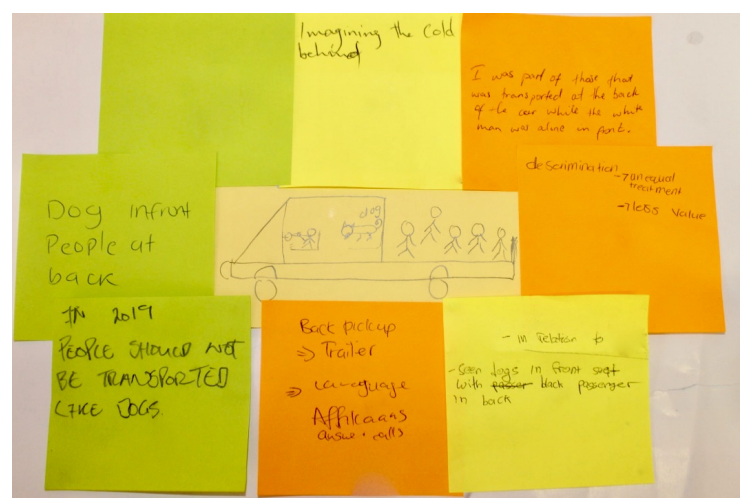

Figure 2: Story flower: dog in passenger seat. @AP Kambunga

physical artifacts, but instead "brought" a wealth of oral stories. Each youth shared their stories while the facilitators created a sticky note representation of the story (drawing or text). Then each listener was given a sticky note to express how they related to the story, creating a set of shared visual story flowers based on narratives that everybody could relate to. One such narrative of local power struggles (Figure 2 below) described local Namibians being transported at the back of a pickup car, by their "white" boss in front with his dogs in the passenger seat.

Strong emotions emerged from this specific story: the young people thought the episode was dehumanizing. In a different case, they indicated that memories of colonialism are triggered by the use of Afrikaans, a colonial language now used in many public service offices as the official language. This prompted discussions about children who often cannot articulate themselves in their indigenous languages but in English, which is perceived as showing off how "educated" one's children are. In the following vignette, one youth recounted his perspective on the location and street names in Windhoek, which are tied to local politics and power:

We have the city designers of Windhoek giving bad location and street names to suburbs where poor people live, while the wealthy live in places with beautiful names. For instance: in Pioneers Park [where the 
wealthy live], the streets are named after pioneers of the German empire. While where the poor people live, locations are given names such as "Donkerhoek" [Dark Corner], Babylon and Golgota. If you are a Christian, you wouldn't want to live in Golgota, let alone in a place called Donkerhoek. How do you expect people from such locations to have big dreams if they live in environments that are not inspiring and motivating? These systems are designed in a way to keep people segregated and without consciousness. Because, lack of consciousness is permanent enslavement. However, the city is spending time and money in efforts of deleting German and South African traces to the point of renaming "Storch street" which has no ill meaning to it rather than paying attention to how these memories affect people and engaging the youth in such discourses.

Probing these oral stories triggered an ongoing dialogue among the youth, who realizing that they all had similar observations and experiences yet different opinions, which they expressed eloquently and eagerly. The oral stories were not only personal, but related to complex politics at all levels of society. Moreover, the narratives were co-created: they emerged through collective inquiry into postcolonial everyday experiences and memories. The focus on oral narratives allowed for profound discussions that might not have emerged using traditional PD methods [45]. Even as local facilitators, however, we were not prepared for the richness and nuance of the stories, or their dynamic development in the group. Documenting the narratives using post-it notes, while also audio recording and trying to continuously visualize/draw the narratives for the group, did not fully capture the diversity of what emerged. The youth however paid little attention to our efforts and materials; they were fully immersed in the lively discussion. Thus, we started to question our own approach to facilitating and representing memory-making in terms of discriminating (colonizing) the flow and exchange of stories and thoughts by attempting to visualize and document, as opposed to the oral representations of the shared narrative.

5.1.4 Provocative archive and newspaper probes. As triggers for one session, we selected current newspaper articles with direct relevance to the postcolonial debates. We matched these with related pre-independence articles from the national Namibian archives. We asserted that current political topics might be particularly intriguing if jointly analyzed within a colonial frame. The youth were presented with a current newspaper article about "Operation Hornkrantz," a military operation launched in 2018 by the Namibian government to clear out criminals in Windhoek. The article reported on an incident in which a taxi-driver was shot by the military involved. The youth were asked to write down their "emotions" on Post-Its (Figure 3, placed around the image), then their "thoughts" about the article (placed in the next circle around the image). In a third stage, the youth debated the topic, and common points were noted on sticky notes placed in the third circle.

Finally, in the fourth stage, the article was replaced with an archive image, now based on the participants "knowing" the link to the past. The archive photo depicted a contemporary article of the

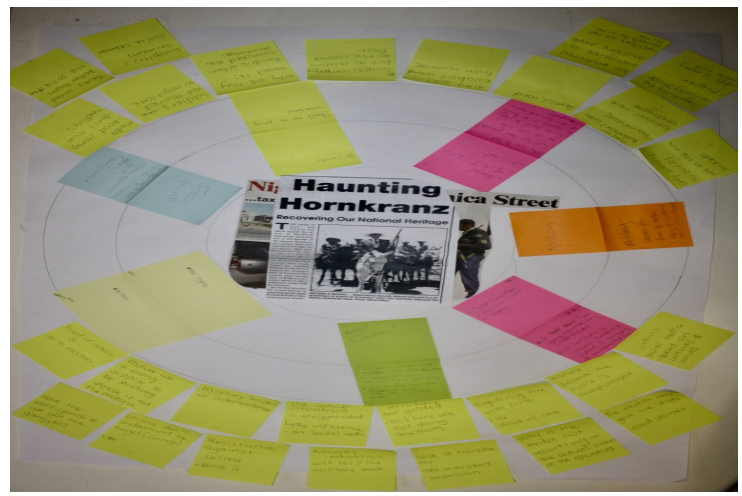

Figure 3: Archive image of Operation Hornkranz replacing article on recent military operation. ๑AP Kambunga

original "Operation Hornkranz" in 1893, when German soldiers attacked the settlement of Hendrik Witbooi, a Nama chief in conflict with the Germans, violently killing mainly women and children of Nama descent. The youth were unaware of this historical event, and reacted with shock to the close resemblance between past and present operations. Through their shared analysis, the youth became aware of intricate connections to colonialism, and they condemned and questioned the current political decision to rename the operation "Hornkranz." Moreover, the youth realized their own lack of awareness of past events-and the necessity of understanding them. Given the results, we found that using provocative probes and establishing historical links had the potential to stimulate critical thinking so that the youth reflected on complex political issues that are ingrained or hidden in their everyday experiences. Discussions continued in other sessions not reported here, and a visit to the Independence Memorial Museum yielded critical analysis of the museum's formal representation of Namibian colonial times, which clearly left out narratives and voices identified by the youth. The different probings created a legitimate forum for collaboratively exploring and generating reflections and experiences of the postcolonial.

\subsection{Engaging with decolonial discourse contributors}

With the aim of positioning the research with the youth in ongoing debates on decolonization in Namibia, we engaged a group of local discourse contributors on decolonization in a workshop. The workshop was organized as a PD workshop with two main aims: first, to explore the local Namibian discourse on decolonization, and second, to address how our PD research methods and approaches could be aligned with and appropriated to these local positions or approaches to decolonization, which we might have been unaware of.

5.2.1 The meaning(s) of decolonization. In the first part of the workshop, participants discussed their personal and professional understanding of "decolonization." Different meanings emerged, identifying at least three perspectives. The first group argued for 


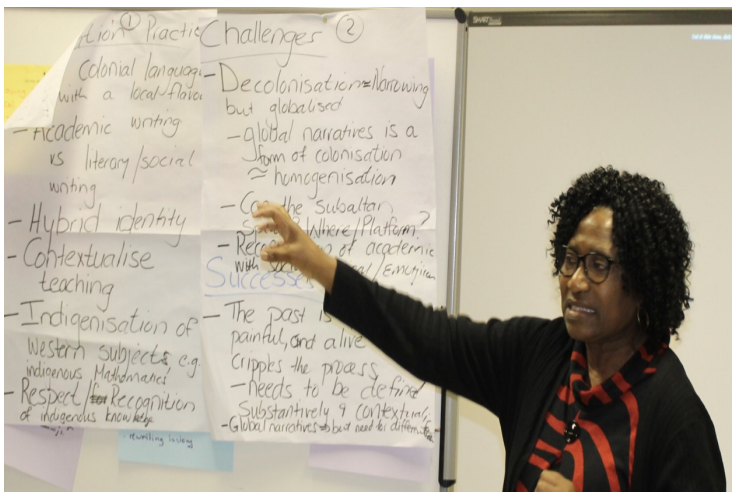

Figure 4: Presenting discussions on decolonization in Namibia $\odot A P$ Kambunga

a necessary local shift in the focus from current debates on postindependence toward a precolonial state of affairs relying on indigenous knowledge systems and local philosophies. The second group focused on freedom of speech and empowering people to tell their stories orally. This group also agreed on the need to abolish political and organizational hierarchies that were created during colonial times. They argued that the systems were not inclusive, and were designed for blacks to not thrive. The third group argued that the wrongs of colonialism should be corrected, starting with respecting and recognizing indigenous languages, liberating people's minds, and questioning power relations.

5.2.2 Decolonization practices in Namibia. Three diverse groups were formed based on the participants' understanding of decolonization. Each group discussed decolonization in the Namibian context, the application of decolonizing methods in their work, and challenges and successes in their engagement of local stakeholders.

During group presentations (see figure 4), the participants agreed that there were no radical decolonial movements in Namibia. Rather, there were separate isolated efforts linked to decolonization, such as reintroducing indigenous languages in schools and support for digitization of indigenous knowledge by the state. Other discourses emerged, for instance on how Wikipedia entries on Namibia still today have almost no indigenous contributions, thereby reinforcing a biased narrative of Namibian history and culture. Another contentious topic was the (re)allocation of land formerly occupied by colonial settlers. Recent government resolutions to "reclaim" the land had opened up new disputes between ethnic tribes over who were the "original" owners. Success stories relating to decolonization in Namibia were also raised, including efforts toward the inclusion of marginalized communities and demands for Namibian role models. The groups also appreciated platforms such as the workshop, which had brought together people with the same agendas.

Discussions on issues that hinder decolonization in Namibia covered how the local communities involved in research projects favoured collaborations with foreigners over local researchers [46]. This kind of approach challenges internal decolonization efforts and makes it difficult to change people's mindsets. The participants believed that local minds -including (us as) researchers-are colonized, because they continue to adopt Western methods without localizing them. This inherently reproduces forms of neocolonialism.

5.2.3 Toward decolonizing methods. Our aim was to involve local decolonial discourse contributors in giving feedback on our approaches and methods for engaging the young Born Frees. We presented details of the project and materials from the sessions with them, including an audio recording of their critical discussions which clearly problematized the issues at hand. However, prompting the participants' input and deliberating on the matter was not followed by the discussions providing us with locally based feedback that we had expected. Rather, this pointed us to issues of community engagement and trust-creation practices, as presented in the mainstream literature.

\section{DISCUSSION}

\subsection{From "third space" to "safe space"}

Our approach to engaging young Namibians in addressing complex matters was to create a "third space" which enabled them to express themselves and engage freely in highly political discourses relating to Namibian postcolonialism. What became clear through the sessions, however, was a lack of awareness and critical reflection among the Born Frees about their postcolonial present and colonial pasts. Moreover, their identities as Born Free led to their experiencing pressure from older generations to make something of the freedom they were born into. Lacking first-hand knowledge of colonization, they are nevertheless affected by its consequences, while not being offered a space for critical discussion or commemoration. Debates and traces of colonialism are ever-present in their surroundings, but rarely included in private conversations or reflected more generally in educational practices. The project provided the "third space" for reflection through probing and dialogue about the young people's cultural realities: discussions took place about everyday forms of postcolonialism and about how memories of the past are entangled in the present. The researchers engaged in the dialogue, defended their disciplinary positions and opinions, and asked probing questions to support the creation of new and different perspectives on certain matters. Here the local researcher's cultural anchoring provided a clear vantage point in the shaping of this space. Through voicing her experiences and guiding the dialogue, the Born Free researcher blurred her role of facilitator and participant, shifting continually between insider/outsider positions. Additionally, the ongoing engagements, the participants' growing familiarity with each other, and the negotiations of shared goals served as an important impetus in creating a space where multiple epistemologies could be nurtured.

Given our context, we assert that we did not merely create a "hybrid space," as described by Muller and Druin [34], for integrating voices of the participants. Rather, these young people were already born into a highly political and cultural "hybrid space," as theorized by Bhabha [8], because hybrid cultures were already a fundamental premise in Namibia. Thus, our use of PD methods to cultivate the "third space" was not sufficient. There was a need for a deeper mutual understanding of the complexities of personal experiences 
and political entanglements at stake, and a need to focus on creating a "safe space" within the third space because of fears and concerns initially voiced by the young people due to the political nature of the project. This safe space became key to enabling mutual learning, shared goals and visions, and their engaging in sensitive discussions. Consequently, we are left with multiple questions that open up new reflections on the question, what kind of third space does a decolonizing PD approach aim to establish?

First, what do we do with the materials, insights, and understandings co-created in the "safe place," which have the potential to open up new ways of (future) memory-making and contribute to the larger decolonization debates in Namibia, yet which create fear of repercussions? Second, what does PD have to offer in addressing such fears in a non-confrontational manner, while building on political potential of PD to shape new publics and understandings? Is PD better suited to working with "visions" in isolated antagonistic initiatives, rather than shaping futures that are deployed into the world to create impact and change? Design as an ontological practice $[15,39]$, we argue, needs to go beyond just enabling multiple voices and engage participants through mutual learning processes. To shape decolonized PD practices calls for us to pay deeper attention to co-creating and engaging in ongoing meaning making processes, diverse epistemologies, and situated cultural change.

\subsection{Decolonizing PD methods}

One aim of the research was to address the approaches that we use as researchers to facilitate a decolonizing PD process. The focus on materials like post-it notes in the youth sessions was a clear example of the way "universal design methods" affect how PD researchers facilitate collaborative sessions, even when conducting research in local contexts and sharing the same cultural values as the participants. The use of "probes" [17] was also a well-known method of inquiring into people's imaginations and experiences. Asking the young people to bring in physical artifacts and images that reflected postcolonialism in their everyday lives did not produce the engagement among the participants that we had expected. Instead, the young people emphasized oral narratives and had long and lively discussions about issues ranging from personal memories and local power struggles to national politics. In their unprocessed and fragmented forms, these narratives became the rich materials from which the sentiments, memories, and narratives were collectively articulated and given shape. Our initial intention had been to focus centrally on oral histories; but in reality, as the process began, we drew upon well-known PD approaches. The triggers that were used-archive images and contemporary newspapersworked well to spur discussions and critical reflections because the young people identified with the media discourses and with their past connections. These tools, although not oral, were situated tools and approaches based on the researchers' cultural insights and knowledge.

Our research clearly demonstrates that reliance on generalized PD methods and techniques is not sufficient for decolonizing design. It also demonstrates that these methods are ingrained with values, assumptions, and generalized ideas that easily come to overshadow the situated cultural contexts of the participants [50]. This raises questions about the ability of researchers in PD to adopt strategies and frameworks such as Brandt et al.'s [11] dynamic approach to "telling-making-enacting," or Muller's [33] "third space," to an extent facilitating rather than suppressing local epistemologies. What our process with the young Namibian Born Frees also vividly demonstrated was that such cultural narratives and memories do not readily exist but are formed dynamically as part of the process itself, relying heavily on local cultural motivations and traditions. For example, only through engaging in a systematic and structured method of deconstructing everyday narratives (such as with the newspaper article) did the young people realize the political connections between past and present events, thereby re-inspecting both. Equally, the desire to voice stories and opinions in open-ended discussions going on for several hours over the session slots was testament to the participants' engagement in both content and format. Decoloniality means "to listen" to the ones who have not been heard; and so PD must support the participants' "takeover" of content, form, and duration.

\subsection{Entanglements and de-linking epistemologies}

From the workshop with the decolonial contributors, it became clear that local discourses on "decolonization" are addressed in theory, but for the most past are often lacking in praxis, as observed by the participants. The discussions demonstrated that in practice many academics continue to operate in a colonized world, using the tenets of postcolonialism rather than those of decoloniality, which would question the present-day order, in which epistemology and ontology are still largely dictated by the Global North, and knowledge production is still Eurocentric [28]. Perhaps, therefore, our quest for input on how to align our PD methods and approaches with local decolonization practices did not yield the results we expected. Moreover, the participants were not sufficiently familiar with PD approaches; they encouraged following Western standardized research structures and practices that were based on discussions of disciplinary boundaries that did not align with our interdisciplinary and collaborative design research.

The discussions about the application of decolonial approaches and methodology, then, in practice failed because we had assumed a shared understanding of decolonialism. The workshop revealed a kind of silence in the groups that had been engaged for this purpose. There were strong societal and intellectual voices in the local decolonization discourse, addressing high-level issues such as the decolonization of the education system, land reform, and other politically relevant matters; but the practical, on-the-ground advice we sought remained absent. One reason for this could be the continued entanglements of postcolonialism in Namibian society in new forms of neocolonialism. Like the young people's narratives, each generation and ethnic group, each geographical cityscape, each media story and academic institution is politically and personally entangled in complex sentiments, guises, and webs of the past and present that are untold, unresolved, unsurfaced, or simply unknown.

This leads us to question the role of the decoloniality discourse in practice, and the (im)possibility of disentangling or de-linking knowledge and epistemologies that are by their very nature always 
already hybrid and entangled. The researchers in this case, although they were themselves local PD researchers, became "third voices" in their own context with the aim of critically exploring plurality, new understandings, and agency among the young people. But they were confronted with the complexity and messiness of the situation, as well as their own lack of coherent or situated approaches to dealing with such issues. Again, voices in a pluriverse were established through the creation of hybrid spaces, and assumptions surfaced and were (re)negotiated. But what was the aim of critically analyzing and bringing forth these (unarticulated) tensions and narratives?

Given that the young people have co-developed an exhibition resulting from the research process, it is precisely the plurality of voices that has been in focus here. But rather than focusing on inclusion or marginalization, our attention has been focused on the "noise" and confusion that very diverse and partial voices actually create in contemporary Namibia. It is clear that a PD approach alone is not sufficient for dealing with such complex issues; and it is also clear that working together with people who share the same decolonial agenda, but come from different fields and have differing positions on developing such practices, is crucial to a future decolonized PD. This would, for example, require the involvement of local discourse leaders over an extended period of time. As MaldonadoTorres [28] points out, decolonization requires teamwork; it is not an individual redemption. Even the progress and development of this paper was only possible because of the diversity of the authors and their positionings in interdisciplinary research fields, along with the intentional framing of a local research project within a larger geopolitical research context.

\section{CONCLUSIONS}

We have contributed to the decolonization discourse in PD through empirical work framed across local and global contexts and disciplinary fields. Based on contemporary discourses of colonialism, we identified not only gaps in the attention paid to such issues by PD, but additionally a lack of empirical cases. Introducing postcolonialism in Namibia as an object of research and design in a practical setting has allowed for new insights beyond the theoretical decolonization discourse. Our participatory approaches to memory-making and decolonizing design with young people in Namibia are framed by values and methods drawn from PD, from design anthropology, and from a shift from postcolonial to decolonial theory. Drawing on this array of values and methods has led to the promotion of local and diverse epistemologies. We envisioned a pluriversal ontological design [15] in which young Namibians' postcolonial memories could become part of prototyping future memory practices and inform new ways of knowing. In our fieldwork, the creation of a "third space" or "hybrid space" for this was replaced by a "safe space" for creating common understandings and narratives, away from local powers and socio-historical complexities. The Born Free young people already occupied a highly hybrid cultural space, having been born into it; they needed an alternative space to reflect on such issues. Further, involving local discourse contributors provided insights into the fact that many global and local academics and intellectuals lack decolonizing strategies and approaches in praxis.
Our research demonstrates that PD approaches provide common ground for participatory memory practices and that they can help to create new discourses that connect past and future experiences with memory-making in the present. However, such approaches also inherently challenge PD's focus on generalized and adaptive methods and tools for engagement, which are often viewed as free of values and assumptions. In our research, such approaches proved much less suitable than oral narratives and local media discourses. This showed us that developing decolonized PD practices is more than just a question of engaging multiple voices, or addressing power relations in the process. Rather, even if we are local researchers, we need to engage more deeply with contextualized political and cultural practices and epistemologies. Even then, engagement alone prompts questions of how to create impact in such highly political cultural settings. Insights from such contexts, however, provide the opportunity to enrich design with new perspectives that may lead to enhanced practices and theories encompassing different epistemologies-including the deployment of these into Western contexts with the aim of creating more inclusive mainstream knowledge systems for the future.

\section{ACKNOWLEDGMENTS}

We thank and acknowledge collaboration with Namibian Born Frees and with decolonial discourse leaders for participating in our research. This project received funding from the European Union's Horizon 2020 research and innovation program under Marie Skłodowska-Curie grant agreement No. 764859.

\section{REFERENCES}

[1] Ebtisam Alabdulqader, Norah Abokhodair, and Shaimaa Lazem. 2017. Designing for the Arab World. In Proceedings of the 2016 ACM Conference Companion Publication on Designing Interactive Systems - DIS '17 Companion, 348-351. https://doi.org/10.1145/3064857.3064860

[2] Syed Mustafa Ali. 2014. Towards a decolonial computing. Ambiguous Technologies: Philosophical Issues, Practical Solutions, Human Nature, International Society of Ethics and Information Technology: 28-35.

[3] Syed Mustafa Ali. 2016. A brief introduction to decolonial computing. XRDS: Crossroads, The ACM Magazine for Students 22, 4: 16-21. https://doi.org/10.1145/ 2930886

[4] Bill Ashcroft, Gareth Griffiths, and Helen Tiffin (eds.). 2006. The post-colonial studies reader. Routledge, London; New York.

[5] Liam Bannon, Jeffrey Bardzell, and Susanne Bødker. 2018. Reimagining participatory design. Interactions 26, 1: 26-32. https://doi.org/10.1145/3292015

[6] Manuhuia Barcham. 2019. Towards a Radically Inclusive Design - Indigenous Story-Telling As Codesign Methodology. SSRN Electronic fournal. https://doi.org/ $10.2139 /$ ssrn.3378742

[7] Heike Becker. 2017. Changing urbanscapes: Colonial and postcolonial monuments in Windhoek. Nordic fournal of African Studies 27, 1. Retrieved from https://www. njas.fi/njas/article/view/266

[8] Homi K. Bhabha. 2004. The location of culture. Routledge, London; New York.

[9] Nicola J. Bidwell. 2016. Decolonising HCI and interaction design discourse: some considerations in planning AfriCHI. XRDS: Crossroads, The ACM Magazine for Students 22, 4: 22-27. https://doi.org/10.1145/2930884

[10] Nicola J. Bidwell, Tigist Sherwaga Hussan, Satinder Gill, Kagonya Awori, and Silvia Lindtner. 2016. Decolonising Technology Design. In Proceedings of the First African Conference on Human Computer Interaction - AfriCHI'16, 256-259. https://doi.org/10.1145/2998581.2998616

[11] Eva Brandt, Thomas Binder, and Elizabeth B.-N Sanders. 2012. Tools and techniques: ways to engage telling, making and enacting. In Routledge International Handbook of Participatory Design. Routledge, 145-181.

[12] Margot Brereton, Paul Roe, Ronald Schroeter, and Anita Lee Hong. 2014. Beyond ethnography: engagement and reciprocity as foundations for design research out here. I $n$ Proceedings of the 32nd annual ACM conference on Human factors in computing systems - CHI '14, 1183-1186. https://doi.org/10.1145/2556288.2557374

[13] Derya Ozcelik Buskermolen and Jacques Terken. 2012. Co-constructing stories: a participatory design technique to elicit in-depth user feedback and suggestions about design concepts. In Proceedings of the 12th Participatory Design Conference 
on Exploratory Papers Workshop Descriptions Industry Cases - Volume 2 - PDC '12, 33-36. https://doi.org/10.1145/2348144.2348156

[14] Arturo Escobar. 2015. Transiciones: a space for research and design for transitions to the pluriverse. Design Philosophy Papers 13, 1: 13-23. https://doi.org/10.1080/ 14487136.2015.1085690

[15] Arturo Escobar. 2018. Designs for the pluriverse: radical interdependence, autonomy, and the making of worlds. Duke University Press, Durham.

[16] Tony Fry. 1999. A new design philosophy: an introduction to defuturing. UNSW Press, Sydney.

[17] Bill Gaver, Tony Dunne, and Elena Pacenti. 1999. Design: Cultural probes. interactions 6, 1: 21-29. https://doi.org/10.1145/291224.291235

[18] Naska Goagoses. 2016. Wishful patchwork: mental contrasting for a common goal. In Proceedings of the 14th Participatory Design Conference on Short Papers, Interactive Exhibitions, Workshops - PDC '16, 63-64. https://doi.org/10.1145/2948076. 2955117

[19] Naska Goagoses, Asnath Paula Kambunga, and Heike Winschiers-Theophilus 2018. Enhancing commitment to participatory design initiatives. In Proceedings of the 15th Participatory Design Conference on Short Papers, Situated Actions, Workshops and Tutorial - PDC '18,1-5. https://doi.org/10.1145/3210604.3210613

[20] Wendy Gunn, Ton Otto, and Rachel Charlotte Smith (eds.). 2013. Design anthropology: theory and practice. Bloomsbury, London; New York.

[21] Human-Computer Interaction Across Borders. Human-Computer Interaction Across Borders. Retrieved from http://www.hcixb.org/

[22] Timothy Ingold and Caroline Gatt. 2013. From description to correspondence: Anthropology in real time. In Design Anthropology: Theory and Practice. ed. Bloomsbury, 139-158.

[23] Lilly Irani, Janet Vertesi, Paul Dourish, Kavita Philip, and Rebecca E. Grinter 2010. Postcolonial computing: a lens on design and development. In Proceedings of the 28th international conference on Human factors in computing systems - CHI '10, 1311. https://doi.org/10.1145/1753326.1753522

[24] Mette Gislev Kjærsgaard, Joachim Halse, Rachel Charlotte Smith, Kasper Tang Vangkilde, Thomas Binder, and Ton Otto (eds.). 2016. Introduction: Design Anthropological Futures. In Design Anthropological Futures.Bloomsbury Academic, $1-16$.

[25] Rosanne van Klaveren. 2018. Towards togetherness: probing as a decolonizing approach. In Proceedings of the 15th Participatory Design Conference on Short Papers, Situated Actions, Workshops and Tutorial-PDC '18, 1-3. https://doi.org/ $10.1145 / 3210604.3214355$

[26] Reinhart Kössler. 2015. Namibia and Germany: negotiating the past. University of Namibia Press, Windhoek, Namibia.

[27] Henry Mainsah and Andrew Morrison. 2014. Participatory design through a cultural lens: insights from postcolonial theory. In Proceedings of the 13th Participatory Design Conference on Short Papers, Industry Cases, Workshop Descriptions, Doctoral Consortium papers, and Keynote abstracts - PDC '14- volume 2, 83-86. https://doi.org/10.1145/2662155.2662195

[28] Nelson Maldonado-Torres. Outline of Ten Theses on Coloniality and Decoloniality*. Retrieved from http://caribbeanstudiesassociation.org/docs/MaldonadoTorres_Outline_Ten_Theses-10.23.16.pdf

[29] Achille Mbembe. 2016. Decolonizing Knowledge and the Question of the Archive. Retrieved from https://wiser.wits.ac.za/system/files/Achille\%20Mbembe $\% 20$ \%20Decolonizing\%20Knowledge\%20and\%20the\%20Question\%20of\%20the\% 20Archive.pdf

[30] Petrus A Mbenzi. 2009. The Management of Place Names in the Post-Colonial Period. Retrieved from https://unstats.un.org/unsd/geoinfo/UNGEGN/docs/25th gegn-docs/wp papers/wp67-place names post colonial period-namibia.pdf

[31] Samantha Merritt and Erik Stolterman. 2012. Cultural hybridity in participatory design. In Proceedings of the 12th Participatory Design Conference on Exploratory Papers Workshop Descriptions Industry Cases - Volume 2 - PDC '12, 73. https://doi.org/10.1145/2348144.2348168

[32] Walter D. Mignolo. 2007. DELINKING: The rhetoric of modernity, the logic of coloniality and the grammar of de-coloniality. Cultural Studies 21, 2-3: 449-514. https://doi.org/10.1080/09502380601162647
[33] Michael Muller. 2009. Participatory Design: THE THIRD SPACE IN HCI. In Human-Computer Interaction, Andrew Sears and Julie Jacko (eds.). CRC Press, 165-185. https://doi.org/10.1201/9781420088892.ch9

[34] Michael Muller and Allison Druin. 2012. Participatory Design: The Third Space in Human- Computer Interaction. In Human-Computer Interaction Handbook. CRC Press, 1125-1154. https://doi.org/10.1201/b11963-57

[35] Luiza Prado de O. Martins and Pedro J. S. Vieira de Oliveira. 2016. Breaking the cycle of Macondo: design and decolonial futures. XRDS: Crossroads, The ACM Magazine for Students 22, 4: 28-32. https://doi.org/10.1145/2930880

[36] Anibal Quijano. 1992. Colonialidad y modernidad/racionalidad'. Peru Indig 13, 29 : $11-20$

[37] Edward W. Said. 1979. Orientalism. Vintage Books, New York.

[38] Chris Saunders. 2017. Decolonization in Southern Africa: Reflections on the Namibian and South African Cases. Journal for Contemporary History 42, 1: 99-114.

[39] Donald A. Schön. 1987. Educating the reflective practitioner: toward a new design for teaching and learning in the professions. Jossey-Bass, San Francisco, Calif.

[40] Tristan Schultz, Danah Abdulla, Ahmed Ansari, Ece Canl, Mahmoud Keshavarz, Matthew Kiem, Luiza Prado de O. Martins, and Pedro J.S. Vieira de Oliveira. 2018. What Is at Stake with Decolonizing Design? A Roundtable. Design and Culture 10, 1: 81-101. https://doi.org/10.1080/17547075.2018.1434368

[41] Jeremy Silvester (ed.). 2015. Re-Viewing Resistance in Namibian History. University of Namibia Press. https://doi.org/10.2307/j.ctvh8qxrv

[42] Linda Tuhiwai Smith. 2012. Decolonizing methodologies: research and indigenous peoples. Zed Books, London.

[43] Rachel Charlotte Smith and Ole Sejer Iversen. 2018. Participatory design for sustainable social change. Design Studies 59: 9-36. https://doi.org/10.1016/j.destud. 2018.05.005

[44] Rachel Charlotte Smith and Mette Gislev Kjærsgaard. 2015. Preface to the Focus Section. IxD\&A 26: 73-80.

[45] Rachel Charlotte Smith and Ton Otto. 2016. Cultures of the future: Emergence and intervention in design anthropology. In Design Anthropological Futures. 19-362.

[46] Rachel Charlotte Smith, Kasper Tang Vangkilde, Mette Gislev Kjaersgaard, Ton Otto, Joachim Halse, and Thomas Binder (eds.). 2016. Design anthropological futures: exploring emergence, intervention and formation. Bloomsbury Academic, an imprint of Bloomsbury Publishing, Plc, London; New York.

[47] Gayatri Chakravorty Spivak. 1988. Can the Subaltern Speak? In Marxism and the Interpretation of Culture. University of Illinois Press, 24-28.

[48] James P. Spradley. 1980. Participant observation. Holt, Rinehart and Winston, New York.

[49] Hildegard Titus. Us Now. Retrieved from http://hildegardtitus.com/

[50] Madina Tlostanova. 2017. On decolonizing design. Design Philosophy Papers 15, 1: 51-61. https://doi.org/10.1080/14487136.2017.1301017

[51] Gerhard Tötemeyer. 2014. Namibia today: challenges and obstacles to reconciliation and stability. Namibia Institute for Democracy, Windhoek.

[52] Elizabeth (Dori) Tunstall. 2013. Decolonizing Design Innovation Design Anthropology, Critical Anthropology, and Indigenous Knowledge. In Design Anthropology: Theory and Practice. Bloomsbury Academic, 232-250. https://doi.org/10. 5040/9781474214698

[53] United Nations. 1978. Security Council Resolution 435. Retrieved from https: //peacemaker.un.org/namibia-resolution435

[54] Heike Winschiers-Theophilus and Nicola J. Bidwell. 2013. Toward an Afro-Centric Indigenous HCI Paradigm. International fournal of Human-Computer Interaction 29, 4: 243-255. https://doi.org/10.1080/10447318.2013.765763

[55] Heike Winschiers-Theophilus, Shilumbe Chivuno-Kuria, Gereon Koch Kapuire, Nicola J. Bidwell, and Edwin Blake. 2010. Being participated: a community approach. In Proceedings of the 11th Biennial Participatory Design Conference on PDC '10, 1. https://doi.org/10.1145/1900441.1900443

[56] Heike Winschiers-Theophilus, Tariq Zaman, and Colin Stanley. 2017. A classification of cultural engagements in community technology design: introducing a transcultural approach. AI \& SOCIETY 34, 3: 419-435. https://doi.org/10.1007/s00146017-0739-y 